\title{
Prevalence of pathological internet use among adolescents in Europe: demographic and social factors
}

\author{
Tony Durkee*1, Michael Kaess*2,3, Vladimir Carli', Peter Parzer², Camilla Wasserman ${ }^{4,5}$, \\ Birgitta Floderus ${ }^{6}$, Alan Apter ${ }^{7}$, Judit Balazs ${ }^{8,9}$, Shira Barzilay ${ }^{7}$, Julio Bobes ${ }^{10,11}$, \\ Romuald Brunner', Paul Corcoran'2, Doina Cosman'13, Padraig Cotter'2, Romain Despalins', \\ Nadja Graber ${ }^{14}$, Francis Guillemin ${ }^{15}$, Christian Haring ${ }^{14}$, Jean-Pierre Kahn ${ }^{16}$, Laura Mandelli, ${ }^{5,17}$, \\ Dragan Marusic ${ }^{18}$, Gergely Mészáros ${ }^{8}$, George J. Musa ${ }^{4}$, Vita Postuvan ${ }^{18}$, Franz Resch ${ }^{2}$, \\ Pilar A. Saiz ${ }^{10,11}$, Merike Sisask ${ }^{19}$, Airi Varnik ${ }^{19}$, Marco Sarchiapone ${ }^{5}$, Christina W. Hoven ${ }^{4,20}$ \& \\ Danuta Wasserman'
}

National Centre for Suicide Research and Prevention of Mental III-Health (NASP), Karolinska Institutet, Stockholm, Sweden', Section for Disorders of Personality Development, Clinic of Child and Adolescent Psychiatry, Centre of Psychosocial Medicine, University of Heidelberg, Heidelberg, Germany², Orygen Youth Health, Melbourne, Australia ${ }^{3}$, Department of Child and Adolescent Psychiatry, Columbia University-New York State Psychiatric Institute, New York, NY, USA ${ }^{4}$, Department of Health Sciences, University of Molise, Campobasso, Italy ${ }^{5}$, Department of Clinical Neuroscience, Karolinska Institutet, Stockholm, Sweden', Feinberg Child Study Centre, Schneider Children's Medical Centre, Tel Aviv University, Tel Aviv, Israel', Vadaskert Child and Adolescent Psychiatric Hospital, Budapest, Hungary, Institute of Psychology, Eotvos Lorand University, Budapest, Hungary99, Department of Psychiatry, School of Medicine, University of Oviedo, Oviedo, Spain ${ }^{10}$, Centro de Investigación Biomédica en Red de Salud Mental (CIBERSAM), Oviedo, Spain ", National Suicide Research Foundation, Cork, Ireland '2, Clinical Psychology Department, Illiu Hatieganu University of Medicine and Pharmacy, Cluj-Napoca, Romania' ${ }^{13}$, Research Division for Mental Health, University for Medical Information Technology (UMIT), Hall in Tirol, Austria' ${ }^{14}$, Inserm CIC-EC, Nancy University Hospital, Nancy, France ${ }^{15}$, Department of Psychiatry, Centre HospitaloUniversitaire de Nancy, Université H. Poincaré, Nancy, France' ${ }^{16}$, Institute of Psychiatry 'P. Ottonello', University of Bologna, Bologna, Italy 17 , Health Research Department, PINT, University of Primorska, Koper, Slovenia ${ }^{18}$, Estonian-Swedish Mental Health and Suicidology Institute, Central Behavior and Health Science, Tallinn University, Tallinn, Estonia' ${ }^{19}$ and Department of Epidemiology, Mailman School of Public Health, Columbia University, New York, NY, USA ${ }^{20}$

\section{ABSTRACT}

Aims To investigate the prevalence of pathological internet use (PIU) and maladaptive internet use (MIU) among adolescents in 11 European countries in relation to demographic, social factors and internet accessibility. Design Cross-sectional survey. Setting The 7th Framework European Union (EU) funded project, Saving and Empowering Young Lives in Europe (SEYLE), is a randomized controlled trial (RCT) evaluating interventions for risk behaviours among adolescents in Austria, Estonia, France, Germany, Hungary, Ireland, Israel, Italy, Romania, Slovenia and Spain, with Sweden serving as the coordinating centre. Participants A total of 11956 adolescents (female/male: 6731/5225; mean age: $14.9 \pm 0.89$ ) recruited from randomly selected schools within the 11 study sites. Measurements Internet users were classified by gender into three categories: adaptive, maladaptive and pathological, based on their score in the Young Diagnostic Questionnaire for Internet Addiction (YDQ). Findings The overall prevalence of PIU was 4.4\%; it was higher among males than females $(5.2 \%$ versus $3.8 \%)$ and differed between countries $\left(\chi^{2}=309.98\right.$; d.f. $=20$; $\left.P<0.001\right)$. PIU correlated significantly with mean hours online and male gender. The highest-ranked online activities were watching videos, frequenting chatrooms and social networking; significantly higher rates of playing single-user games were found in males and social networking in females. Living in metropolitan areas was associated with PIU. Students not living with a biological parent, low parental involvement and parental unemployment showed the highest relative risks of both MIU and PIU. Conclusions Across a range of countries in Europe, using the Young Diagnostic Questionnaire for Internet Addiction yields a prevalence of "pathological internet use' of $4.4 \%$ among adolescents, but varies by country and gender; adolescents lacking emotional and psychological support are at highest risk.

Keywords Adolescents, internet addiction, mental health, pathological internet use, risk-behaviors, school-based prevention, SEYLE.

Correspondence to: Danuta Wasserman, National Centre for Suicide Research and Prevention of Mental Ill-Health (NASP), Karolinska Institutet, Stockholm, 171 65, Sweden. E-mail: danuta.wasserman@ki.se

Submitted 28 July 2011; initial review completed 5 October 2011; final version accepted 9 May 2012

*Both authors contributed equally to this paper, therefore both should be considered as first authors. 


\section{INTRODUCTION}

Internet use has grown exponentially world-wide to nearly 2 billion users [1], with the majority being adolescents and young people [2]. Internet use plays an integral part in many adolescents' daily lives, yet the effects of internet use on adolescents' emotional and behavioural development remains ambiguous [3,4].

Pathological internet use (PIU), also referred to as internet addiction [5-7], has been gaining attention in recent years, due partly to its potential inclusion in the Diagnostic and Statistical Manual of Mental Disorders, 5th edition (DSM-V) classification [8,9]. PIU, to date, has been conceptualized as an impulse control disorder [10], sharing characteristics with behavioural addiction $[11,12]$; however, it still lacks a universal definition and diagnostic criteria.

The terminology used in describing the condition is relatively inconsistent. Internet addiction suggests that individuals become addicted to the internet medium; however, research indicates that the actual addiction is associated with the use of specific online activities $[13,14]$. The term 'pathological internet use' underscores the importance of 'internet use' in the cue-reactivity of underlying pathology. Explicit definitions and terminology are needed in order to reduce discrepancies found in current PIU research, particularly when assessing prevalence [8-12,15].

Epidemiological studies on PIU prevalence have reported large variations. Three US surveys measuring PIU prevalence ranged from $0.7 \%$ to $8.1 \%$ [16-19]. In Asia, findings indicated even higher variations of PIU prevalence among adolescents and young people, ranging from $2.4 \%$ [20] to $37.9 \%$ [21-26]. Research on similar age groups in Europe has shown the following PIU prevalence: 2\% in Norway, 3.1\% in Finland [27], 5.4\% in Italy [28], 5.8\% in Poland [29], 8.2\% in Greece [30] and $18.3 \%$ in England. Thirty per cent of the papers depicted here used the Young Diagnostic Questionnaire for Internet Addiction (YDQ) [31] to measure PIU [20,24,30,32]. The remaining 70\% used distinct diagnostic criteria for PIU assessment. These large variations in the reported prevalence of PIU could be due to diverse methodologies, taxonomy of PIUs and time-frame of the study performed.

Male gender [30,33,34], low parental involvement [35], negative peer relationships [36] and parental unemployment [37] have been implicated as important contributing factors of PIU. Studies on risk behaviours have shown correlations with household composition in deprived areas [38], belonging to a cultural minority [39], and an inverse relationship with religiosity [40]. It is plausible that PIU is associated with these sociodemographic factors; however, to our knowledge, no study has examined all of these potential relationships using the same material.

Research suggests a linear relationship between addiction and accessibility [41-44]. For example, in a metaanalysis, Carter \& Tiffany [45] found that individuals with substance abuse addictions experienced specific cue reactions when exposed to the respective substance stimuli. Similarly, this phenomenon could apply to PIU and internet accessibility.

The key objectives of this study are to map the prevalence of PIU among adolescents in different European countries and examine potential cross-national differences, and to assess its association with gender, internet accessibility, population distribution, household composition, adolescent or parent(s) born in another country, parental involvement and unemployment, peer relationships and religiosity.

\section{METHODS}

\section{Description of study sample}

The present study was conducted within the framework of the EU funded project, Saving and Empowering Young Lives in Europe (SEYLE), a randomized controlled trial (RCT) evaluating preventive interventions of risk behaviours in European school-based adolescents. The detailed protocol of SEYLE has been published elsewhere [46]. The SEYLE study comprises a sample of 12395 adolescents recruited from 178 randomly selected schools, within 11 study sites, in the following European countries: Austria, Estonia, France, Germany, Hungary, Ireland, Israel, Italy, Romania, Slovenia and Spain, with Sweden serving as the coordinating centre. All questionnaires were administered in the official language of the respective country. In each country, a list of all eligible schools within the study sites was generated according to specific inclusion and exclusion criteria [46]. Ethical approval was obtained from the local ethical committees at each study site. Baseline evaluations were performed during the autumn of 2009 (in eight countries) and spring 2010 (in three countries). The overall rate of consent in the first eight countries was $76 \%$. In the latter three countries, extended procedures for the collection of informed consent were imposed by the local ethics committees (i.e. the pupil and both parents were required to sign multiple consent forms). This resulted in the postponement of student recruitment, thereby lowering the rate of consent in these respective countries. When including the remaining three countries in the analysis, the overall rate of consent decreased to $49 \%$. Patterns of association seen in the analysis based on the full sample were very similar to those found in the analysis that excluded the three countries with lower consent (see 
Tables S1-S4 available as supporting information with the online version of this paper; details are given at the end). This suggests that the external validity of our sample is high. A total of 12395 students completed the questionnaire, yielding a participation rate of $88 \%$. There were 1720 students absent on the day of the survey. An additional 439 subjects were excluded based on missing data in gender or in the YDQ, which was used to measure pathological internet behaviours. This resulted in a total sample of 11956 adolescents (female/ male: 6731/5225; mean age: $14.9 \pm 0.89$ ) included in these analyses.

\section{Outcome measures}

A structured questionnaire was administered to adolescents between October 2009 and October 2010, which included the YDQ [31] for measuring PIU. The YDQ was developed according to the DSM-IV diagnostic criteria for pathological gambling; the scale was modified to the distinctive conditions of PIU and validated in previous internet investigations [30,32,34,47]. The YDQ diagnosis is based on a pattern of internet use, over the past 6 months, resulting in clinical impairment or distress $[10,31]$. The criteria are evaluated through eight 'yes' or 'no' questions, with a total score ranging from 0 to 8 (see Appendix). A scoring method identifying three subcategories of severity has been utilized in other studies using the YDQ $[19,32,34]$; thus, the same measures were used in the present study. To better reflect the taxonomy of internet users $[12,48]$, the following categorical terms were used: 'adaptive users' (scoring: 0-2), 'maladaptive users' (scoring: 3-4) and 'pathological users' (scoring: $\geq 5$ ). Information regarding the average number of hours spent online per day for non-essential purposes (e.g. not for schoolwork) and specific online activities were also obtained. Data were collected on demographics, household composition, place of birth, parental involvement, peer relationships, parental unemployment and religiosity using questions procured from the Global SchoolBased Pupil Health Survey (GSHS) [49] and European Values Study (EVS) [50]. Data on national levels of internet accessibility were obtained from Eurostat [51].

\section{Representativeness of the study sample}

Within each study site, schools were selected randomly to participate in SEYLE. To interpret the potential representativeness of the sample, key parameters such as mean age, number of immigrants, population density, net income and gender proportion for each site were compared to the corresponding national data. Data at the national and local levels were extracted from Eurostat [52].

\section{Statistical analyses}

Effect sizes of mean age and number of immigrants at the national and study site levels were calculated for each country according to Cohen's $d$ [53,54], measured as small $(d=0.3)$, medium $(d=0.5)$ and large $(d=0.8)$. Differences in gender distribution among 15-year-olds at the country and study site levels were evaluated with a test of proportions [55]. Population density was compared between each country and the respective study site. Metropolitan and micropolitan areas were defined as $>50000$ and $<50000$ inhabitants, respectively. Categorical and total scores of the YDQ were calculated independently. Descriptive analysis was used to determine the prevalence of adaptive, maladaptive and pathological users, and was calculated separately for gender and country. Prevalence was compared between countries by Bonferroni-adjusted Wald test after a multinomial regression analysis, with internet user group as the dependent variable and country as the explanatory factor. Mean hours online per day were compared between internet user groups and gender, with a two-factor analysis of variance. The association between internet user group and the different online activities were estimated with Goodman \& Kruskal's Gamma separately for males and females; likelihood ratio tests were used to compare gender differences. A multinomial regression analysis was calculated, with internet user group as the dependent variable and social factors as the explanatory variables. A linear regression model was also calculated using the total score of the YDQ to confirm results with a dimensional approach. In $21.2 \%$ of the subjects $(n=2534)$, there was at least one missing value in one of the 16 explanatory variables used in the regression analysis. Among these subjects, $16.8 \%$ showed only one missing item, while the remaining $4.4 \%$ presented a range of two to seven missing items. The largest number of study subjects, with at least one missing value, was reported in Israel $(n=517)$, and the lowest was found in Spain $(n=94)$. In order to prevent estimation bias resulting from the exclusion of these subjects, missing values were replaced with imputed values, using the multivariate imputation by chained equations algorithm [56]. The regression was then calculated for the imputed data sets and the results were combined [57]. A significance level of $\alpha=0.05$ was chosen.

\section{RESULTS}

\section{Characteristics of the study sites and study sample}

Very small effect sizes were found concerning variations in the mean age between study sites and the respective country. Cohen's $d$ effect size remained lower than 0.3, even when stratifying the analysis by gender. The largest 
effect size was found in Spain $(d=0.205)$. For all other countries, the effect size of age was below 0.1. The differences in the proportion of 15-year-old males and females and the respective country's data were not statistically significant. The effect size concerning differences in the number of immigrants at the country and study site levels was lower than 0.3 in all countries, with the exception of Ireland $(d=0.365)$. Population density at the study site level was higher than the respective country in Estonia, Germany, Hungary, Ireland and Spain. Population density was lower at the study site levels in Austria, France, Italy, Romania and Slovenia. The difference in net income per inhabitant was below $10 \%$, with the exception of Estonia $(+17 \%)$, Germany $(+15 \%)$, Hungary $(+42 \%)$ and Italy $(-24 \%)$. The average net income for all countries was not significantly different from the average net income for all study sites $(t=-0.19 ; P=0.985)$. Based on these parameters, the adolescents participating in the SEYLE study are reasonably representative of their respective countries.

\section{Prevalence of maladaptive and pathological internet use}

The prevalence of maladaptive internet use (MIU) and PIU of the total sample was $13.5 \%$ and $4.4 \%$, respectively (Table 1). Overall, female students had a slightly higher prevalence of MIU (14.3\% in females versus $12.4 \%$ in males), while males reported a significantly higher prevalence $\left(\chi^{2}=19.50\right.$; d.f. $\left.=2 ; P<0.001\right)$ of PIU $(5.2 \%$ in males versus $3.8 \%$ in females). Cross-national gender variations in the prevalence of both MIU and PIU were observed. Concerning MIU, Estonia and Slovenia showed a higher prevalence among males than females, while the opposite was found in Romania; the remaining countries had similar gender rates. Regarding PIU, small variations were found between male and female students in all countries except Israel, where males had a two-fold higher prevalence than females.

Significant country differences were found in both MIU and PIU $\left(\chi^{2}=309.98\right.$; d.f. $\left.=20 ; P<0.001\right)$. The highest rate of MIU (18.2\%) and PIU (11.8\%) was found in Israel and the lowest in Italy (8.8\% and 1.2\%). Results of the post-hoc pairwise comparisons of MIU and PIU for all countries are described in Tables 2 and 3.

\section{Mean hours online and online activities}

Mean hours spent online per day in all internet user groups are presented in Table 4. Overall, there were significant differences of time spent online between the different internet groups $\left(F_{(2,11566)}=480.11 ; P<0.001\right)$; there was almost a two-fold increase of hours spent online between the MIU group (mean =1.98) and the PIU group $($ mean $=3.75$ ). These results suggest a dose- response relationship between increased time spent online and the level of addiction. A linear trend between YDQ categories and hours online was confirmed $\left(F_{(1)=953.97} ; P<0.001\right)$ with orthogonal polynomial contrasts. Males spent more hours online than females $\left(F_{(1,11566)}=27.4 ; P<0.001\right)$. This gender effect was equal in all three internet user groups (interaction of gender and internet user group: $\left.F_{(2,11566)}=2.16 ; P=0.12\right)$.

Online activities for each internet user group, stratified by gender, are presented in Table 5. The most frequent online activities among students were watching videos, downloading music, social networking and e-mailing. Associations between YDQ categories and online activities are presented in Table 6. Generally, there were positive correlations between the YDQ categories and each online activity, with the exception of schoolwork, which showed a negative correlation $(P<0.001)$. Results depicted in Table 6 confirm a dose-response relationship between online activities and criteria of PIU. The highest-ranked correlations in the sample were found for watching videos, followed by chatrooms and social networks. Online activities also varied by gender; male students showed the highest correlation with playing online multi-user games, watching videos and playing online single-user games, whereas female students with watching videos, social networking and frequenting chatrooms. Highly significant gender differences were found regarding the engagement in social networks and playing online single-user games.

\section{Internet accessibility}

Internet accessibility rates for each participating European country during 2002-10 are illustrated in Fig. 1. There was a clear trend over time of increasing internet accessibility rates in all participating countries. The multinomial analysis indicated no significant increase in relative risk of MIU or PIU in relation to internet accessibility. A statistically significant, but very weak, association was found between internet accessibility and YDQ total scores $(\beta=0.006 ; P<0.001)$.

\section{Demographic and social risk factors}

Relative risk of MIU and PIU in relation to several demographic and social conditions is presented in Table 7 . The results indicated that females were more likely to engage in MIU, while males had a greater risk of PIU (Table 6) [relative risk ratio $(\mathrm{RRR})=1.25$; confidence interval $(\mathrm{CI})$ : 1.04-1.50]. Age was not found to be a significant factor. Among students living in metropolitan areas, there was a significant increase in the relative risk of both MIU $($ RRR = 1.26; CI: 1.12-1.42) and PIU (RRR = 1.40; CI: 1.15-1.71). Students who did not live with a biological parent or relative had the highest risk of both MIU 


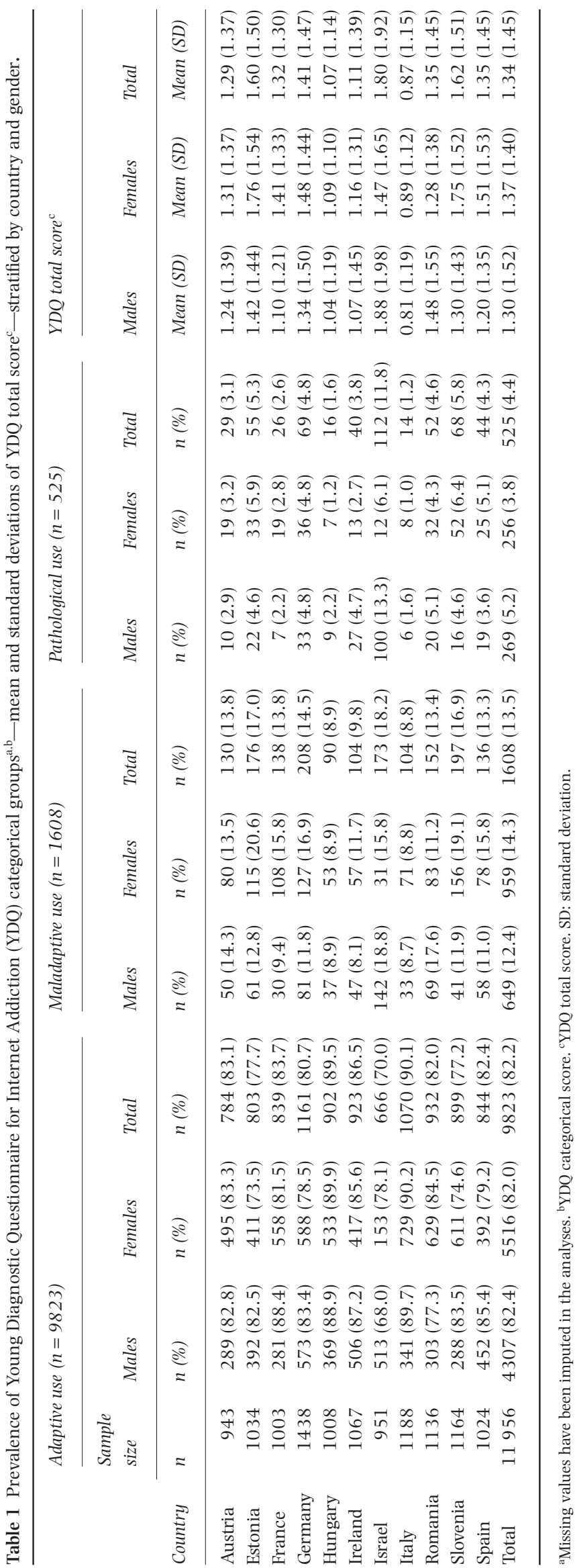


Table 2 Significance of post-hoc pairwise comparison of maladaptive internet users (MIU). ${ }^{\text {a }}$

\begin{tabular}{|c|c|c|c|c|c|c|c|c|c|c|c|}
\hline \multicolumn{12}{|c|}{ Maladaptive use $(n=1608)$} \\
\hline Country & Austria & Estonia & France & Germany & Hungary & Ireland & Israel & Italy & Romania & Slovenia & Spain \\
\hline Austria & - & NS & NS & NS & 0.05 & NS & 0.05 & 0.01 & NS & NS & NS \\
\hline Estonia & & & NS & NS & $<0.01$ & $<0.01$ & NS & $<0.01$ & NS & NS & NS \\
\hline France & & & & NS & NS & NS & 0.03 & 0.01 & NS & NS & NS \\
\hline Germany & & & & & $<0.01$ & 0.03 & NS & $<0.01$ & NS & NS & NS \\
\hline Hungary & & & & & & NS & $<0.01$ & NS & 0.05 & $<0.01$ & NS \\
\hline Ireland & & & & & & & $<0.01$ & NS & NS & $<0.01$ & NS \\
\hline Israel & & & & & & & & $<0.01$ & 0.02 & NS & 0.02 \\
\hline Italy & & & & & & & & & 0.01 & $<0.01$ & 0.03 \\
\hline Romania & & & & & & & & & & NS & NS \\
\hline Slovenia & & & & & & & & & & & NS \\
\hline Spain & & & & & & & & & & & - \\
\hline
\end{tabular}

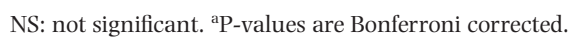

Table 3 Significance of post-hoc pairwise comparison of pathological internet users (PIU). ${ }^{\mathrm{a}}$

Pathological use $(n=525)$

\begin{tabular}{|c|c|c|c|c|c|c|c|c|c|c|c|}
\hline Country & Austria & Estonia & France & Germany & Hungary & Ireland & Israel & Italy & Romania & Slovenia & Spain \\
\hline Austria & - & NS & NS & NS & NS & NS & $<0.01$ & NS & NS & NS & NS \\
\hline Estonia & & & NS & NS & $<0.01$ & NS & $<0.01$ & $<0.01$ & NS & NS & NS \\
\hline France & & & & NS & NS & NS & $<0.01$ & NS & NS & 0.02 & NS \\
\hline Germany & & & & & $<0.01$ & NS & $<0.01$ & $<0.01$ & NS & NS & NS \\
\hline Hungary & & & & & & NS & $<0.01$ & NS & 0.01 & $<0.01$ & 0.03 \\
\hline Ireland & & & & & & & $<0.01$ & 0.01 & NS & NS & NS \\
\hline Israel & & & & & & & & $<0.01$ & $<0.01$ & $<0.01$ & $<0.01$ \\
\hline Italy & & & & & & & & & $<0.01$ & $<0.01$ & $<0.01$ \\
\hline Romania & & & & & & & & & & NS & NS \\
\hline Slovenia & & & & & & & & & & & NS \\
\hline Spain & & & & & & & & & & & - \\
\hline
\end{tabular}

NS: not significant. ${ }^{\mathrm{a} P-v a l u e s}$ are Bonferroni corrected.

Table 4 Mean hours online per day for each Young Diagnostic Questionnaire for Internet Addiction (YDQ) categorical group, ${ }^{\text {a }}$ stratified by gender. ${ }^{\text {b }}$

\begin{tabular}{|c|c|c|c|c|c|c|c|c|c|c|c|c|c|c|}
\hline & \multicolumn{4}{|c|}{ Adaptive users $(n=9529)$} & \multicolumn{5}{|c|}{ Maladaptive users $(n=1557)$} & \multicolumn{5}{|c|}{ Pathological users $(n=487)$} \\
\hline & Male & \multicolumn{2}{|c|}{ Female } & \multirow[b]{2}{*}{ Total } & \multicolumn{2}{|l|}{ Male } & \multicolumn{2}{|c|}{ Female } & \multirow[b]{2}{*}{ Total } & \multicolumn{2}{|l|}{ Male } & \multicolumn{2}{|c|}{ Female } & \multirow[b]{2}{*}{ Total } \\
\hline & Mean SD & Mean & $S D$ & & Mean & $S D$ & Mean & $S D$ & & Mean & $S D$ & Mean & $S D$ & \\
\hline Mean hours online/day & $2.11 \quad 1.66$ & 1.88 & 1.40 & 1.98 & 3.27 & 2.42 & 2.84 & 1.84 & 3.01 & 3.89 & 2.59 & 3.62 & 2.53 & 3.75 \\
\hline
\end{tabular}


at the $\mathrm{P}<0.001$ level. SD: standard deviation.

$(\mathrm{RRR}=1.93 ;$ CI: 1.32-2.81) and PIU $(\mathrm{RRR}=3.00$; CI: 1.86-4.86); having no siblings had no significant impact on the relative risk of MIU or PIU, even if a significant association with a higher YDQ score $(\beta=0.105$; $P=0.002)$ was observed. Adolescents born in another country did not indicate an increased risk of MIU or PIU; significantly higher relative risk of MIU was found among students with fathers born in another country $(\mathrm{RRR}=$ 1.30; CI: 1.07-1.58); however, this association was not significant for PIU or for mothers born in another country. 


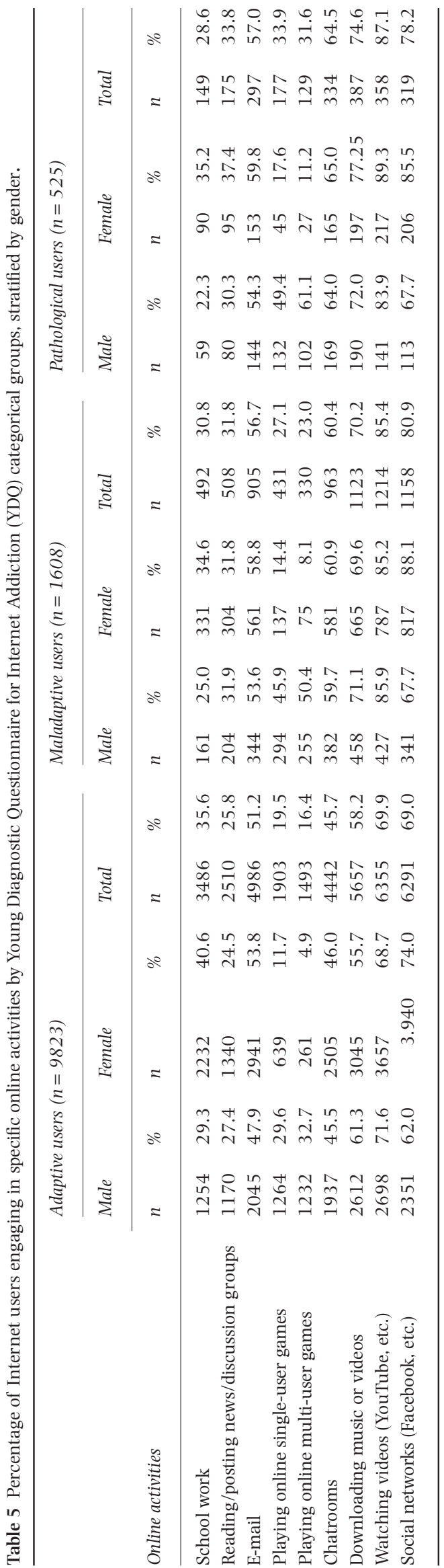

Concerning low parental involvement, relative risks were exceedingly high for both MIU and PIU among adolescents perceiving that their parents: 'do not understand them' (RRR = 1.70; CI: $1.50-1.94$ and RRR = 2.14; CI: 1.70-2.68); 'do not know what adolescent does with free time' (RRR = 1.87; CI: $1.66-2.10$ and RRR = 1.93; CI: 1.58-2.35); and 'does not pay attention to the adolescent' $(\mathrm{RRR}=1.46$; CI: $1.30-1.65$ and $\mathrm{RRR}=2.20$; CI: 1.78-2.71). Concerning peer relationships, students who reported a steady boyfriend/girlfriend had an increased risk of MIU and PIU (RRR = 1.16; CI: 1.02-1.32 and RRR = 1.61; CI: 1.32-1.96). Students with unemployed parents/guardians indicated significantly higher risk of $\mathrm{MIU}$ and PIU $(\mathrm{RRR}=1.38 ; \mathrm{CI}$ : $1.17-1.63$ and RRR = 1.68; CI: 1.31-2.16). Religiosity was not a significant factor for either MIU or PIU. The linear regression analysis (table 8) confirmed the results found in the multinomial regression.

\section{DISCUSSION}

Many European adolescents today are exposed to a reality of frequent computer use. However, research regarding the influence of PIU on the emotional and behavioural development of adolescents is still lacking in scope and clarity. To our knowledge, this is the first time that the prevalence of PIU has been assessed within the same time-frame and using a homogeneous methodology on a large multi-national sample of European adolescents. With respect to the large sample size, and the fact that the study sites have been shown to be representative of the respective countries, these findings can be considered generalizable within each of the 11 participating countries.

Generally, males had a higher prevalence of PIU, while females reported higher MIU; this is consistent with previous research $[30,32,34]$. It appears that females have a greater tendency to use the internet until a certain threshold (MIU), without reaching the level of PIU observed frequently among males. Studies show that males tend to abuse addictive substances more often than females [58]; this indicates that there are gender variances in the severity of dependency [59]. Whether this occurs on account of social or neurobiological factors [60-62], the different addictive pathways between genders should be examined in prospective research.

Overall, the prevalence of PIU among males and females was highest in Israel, while the lowest was found in Italy. The cross-national variations in prevalence applied to both genders, however, were most pronounced among males. This suggests that both gender and sociocultural aspects influenced the prevalence of PIU.

No significant correlation between PIU and national levels of internet accessibility was found in the multinomial analysis; however, the linear regression model 
Table 6 Associations between Young Diagnostic Questionnaire for Internet Addiction (YDQ) categories and online activities, stratified by gender.

\begin{tabular}{lcccc}
\hline Online activities & $\begin{array}{l}\text { Male } \\
\text { Gamma* }\end{array}$ & $\begin{array}{l}\text { Female } \\
\text { Gamma* }\end{array}$ & $\begin{array}{l}\text { Total } \\
\text { Gamma* }\end{array}$ & $\begin{array}{l}\text { Gender differences } \\
\text { P-value }\end{array}$ \\
\hline School work & -0.126 & -0.120 & -0.119 & 0.738 \\
Reading/posting news/discussion groups & 0.090 & 0.201 & 0.152 & 0.031 \\
E-mail (reading, writing) & 0.113 & 0.103 & 0.107 & 0.978 \\
Playing online single-user games & 0.343 & 0.146 & 0.245 & 0.001 \\
Playing online multi-user games & 0.396 & 0.294 & 0.257 & 0.279 \\
Chat rooms & 0.296 & 0.303 & 0.300 & 0.960 \\
Downloading music or videos & 0.215 & 0.321 & 0.276 & 0.025 \\
Watching videos (YouTube, etc.) & 0.385 & 0.468 & 0.436 & 0.113 \\
Social networks (Facebook, etc.) & 0.119 & 0.411 & 0.283 & $<0.001$
\end{tabular}

*Goodman \& Kruskal's Gamma is a measure for the association between ordered categories and ranges from -1 to +1 and is interpreted in analogy to a correlation coefficient.

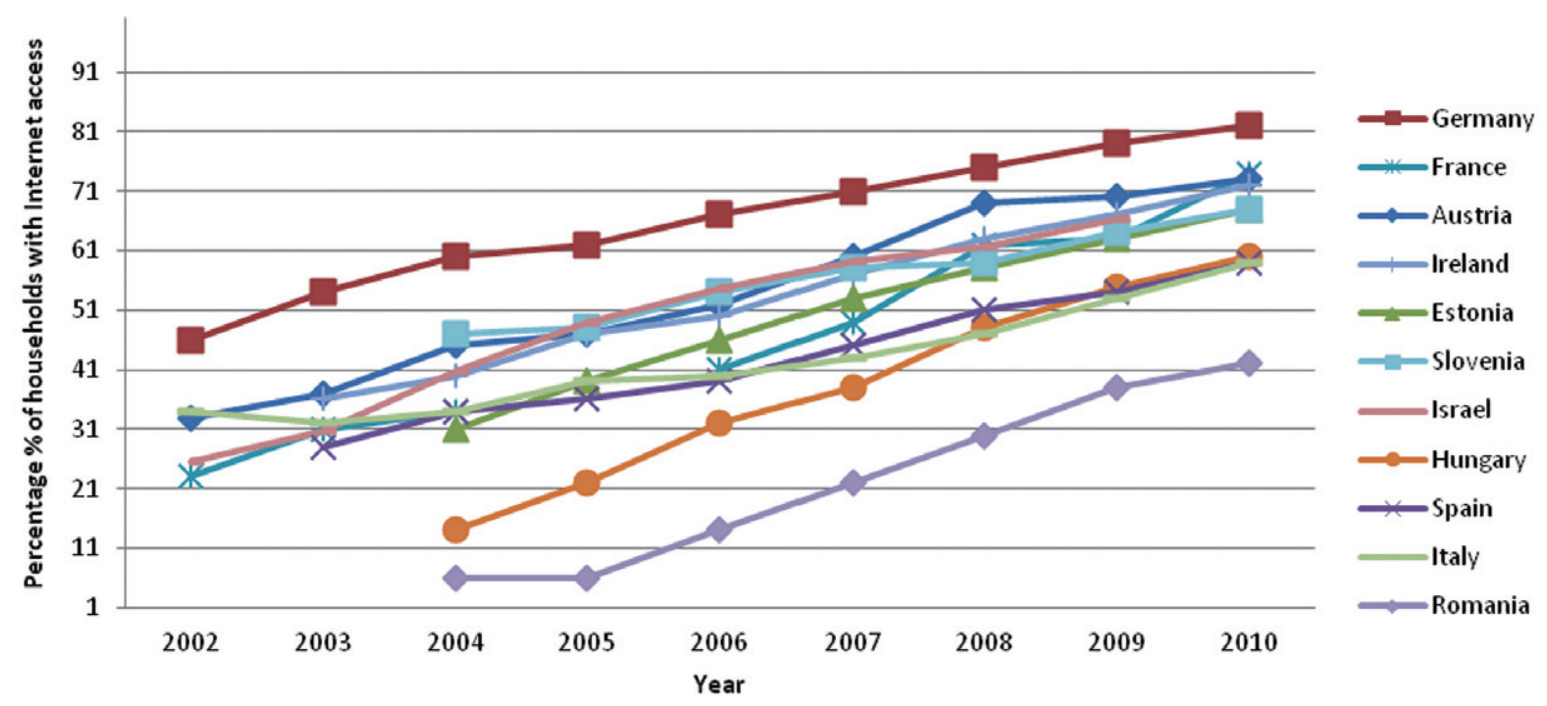

Figure I Percentage of households with internet accessibility by country, 2002-10.ab Sources: aEurostat [5 I] and Central Bureau of Statistics (CBS) for Israel [73]. ' Countries were ranked from highest to lowest, based on the percentage of households with internet access

indicated a very weak association. Lack of significant outcomes, in the multinomial analysis, could be due to the relatively high rates of internet access across Europe; the fact that access rates were measured at the national level and compared to MIU and PIU on the individual level may be confounding factors. Despite the slight increase observed between accessibility and YDQ total score, the results from this study suggest that internet access is not a crucial factor in the prevalence of MIU and PIU.

When assessing metropolitan versus micropolitan areas, results indicated clearly that adolescents living in metropolitan areas had an increased risk of both MIU and PIU. This is an important finding, as it suggests that specific factors in metropolitan areas increase the risk of PIU among adolescents. It remains unclear whether these factors are connected to internet accessibility, population size, intercultural differences, economic factors or other socio-demographic characteristics; further studies are necessary to disentangle these components.

Van Rooij et al. [13] and Kormas et al. [63] suggest that specific online activities may be more addictive than others; our results substantiated that gender-specific online activities were correlated with PIU. Playing online games was the predominant activity for males and increased nearly two-fold from adaptive use to pathological use. Conversely, females often used the internet for social networks and e-mail. The largest percentage of social networking was found among females with MIU, confirming previous findings [64-66]. Social networking has been found to confer significant benefits for adolescents suffering from social exclusion and isolation $[67,68]$; hence, females may use it as a coping strategy, thereby precluding PIU. 
Table 7 Multinomial regression model of Young Diagnostic Questionnaire for Internet Addiction (YDQ) categories by demographic and social factors. ${ }^{a}$

\begin{tabular}{|c|c|c|c|c|c|c|c|}
\hline \multirow{3}{*}{\multicolumn{2}{|c|}{ Demographic and social factors }} & \multirow{2}{*}{\multicolumn{3}{|c|}{$\begin{array}{l}\text { Maladaptive use }(n=1608) \\
\text { Multivariate analysis }\end{array}$}} & \multirow{2}{*}{\multicolumn{3}{|c|}{$\begin{array}{l}\text { Pathological use }(n=525) \\
\text { Multivariate analysis }\end{array}$}} \\
\hline & & & & & & & \\
\hline & & $R R R$ & $95 \% C I$ & $P$ & $R R R$ & $95 \% C I$ & $P$ \\
\hline \multicolumn{2}{|l|}{ Age } & 0.99 & $0.93-1.06$ & 0.841 & 1.02 & $0.92-1.13$ & 0.697 \\
\hline \multicolumn{2}{|l|}{ Male gender } & 0.82 & $0.73-0.91$ & $<0.001$ & 1.25 & $1.04-1.50$ & 0.016 \\
\hline \multicolumn{2}{|l|}{ Internet accessibility } & 1.00 & $1.00-1.01$ & 0.232 & 1.01 & $1.00-1.02$ & 0.077 \\
\hline \multicolumn{2}{|l|}{ Metropolitan areas } & 1.26 & $1.12-1.42$ & $<0.001$ & 1.40 & $1.15-1.71$ & 0.001 \\
\hline \multirow[t]{2}{*}{$\begin{array}{l}\text { Household } \\
\text { composition }\end{array}$} & $\begin{array}{l}\text { Student does not live with biological parent or } \\
\text { relative }\end{array}$ & 1.93 & $1.32-2.81$ & 0.001 & 3.00 & $1.86-4.86$ & $<0.001$ \\
\hline & Student has no siblings & 1.14 & $0.99-1.31$ & 0.075 & 1.26 & $0.99-1.61$ & 0.058 \\
\hline \multirow{3}{*}{$\begin{array}{l}\text { Birth in another } \\
\text { country }\end{array}$} & Father of student was born in another country & 1.30 & $1.07-1.58$ & 0.007 & 0.84 & $0.60-1.18$ & 0.313 \\
\hline & Mother of student was born in another country & 1.01 & $0.83-1.24$ & 0.888 & 1.25 & $0.90-1.74$ & 0.181 \\
\hline & Student was born in another country & 0.92 & $0.72-1.17$ & 0.499 & 1.08 & $0.73-1.61$ & 0.684 \\
\hline \multirow{3}{*}{$\begin{array}{l}\text { Parental } \\
\text { involvement }\end{array}$} & Parents do not understand student's problems & 1.70 & $1.50-1.94$ & $<0.001$ & 2.14 & $1.70-2.68$ & $<0.001$ \\
\hline & $\begin{array}{l}\text { Parents do not know what student does with } \\
\text { free time }\end{array}$ & 1.87 & $1.66-2.10$ & $<0.001$ & 1.93 & $1.58-2.35$ & $<0.001$ \\
\hline & Parents do not pay attention to student & 1.46 & $1.30-1.65$ & $<0.001$ & 2.20 & $1.78-2.71$ & $<0.001$ \\
\hline \multirow[t]{2}{*}{ Peer relationships } & Student has a steady boyfriend/girlfriend & 1.16 & $1.02-1.31$ & 0.024 & 1.61 & $1.32-1.96$ & $<0.001$ \\
\hline & Student has no close friends & 1.33 & $0.87-2.02$ & 0.191 & 1.38 & $0.72-2.61$ & 0.329 \\
\hline $\begin{array}{l}\text { Parental } \\
\text { unemployment }\end{array}$ & Unemployment of student's parent/guardian & 1.38 & $1.17-1.63$ & $<0.001$ & 1.68 & $1.31-2.16$ & $<0.001$ \\
\hline Religiosity & $\begin{array}{l}\text { Student perceived himself/herself as a } \\
\text { religious person }\end{array}$ & 1.07 & $0.95-1.20$ & 0.242 & 1.17 & $0.96-1.41$ & 0.114 \\
\hline
\end{tabular}

aThe regression coefficients are presented in their exponential form as relative risk ratios with adaptive internet use as base category. RRR: relative risk ratio; CI: confidence interval. Significance level of $P<0.05$.

Table 8 Linear regression model of Young Diagnostic Questionnaire for Internet Addiction (YDQ) total score by demographic and social factors ${ }^{\mathrm{a}}$.

\begin{tabular}{|c|c|c|c|c|}
\hline & & \multicolumn{3}{|c|}{$Y D Q$ total score } \\
\hline & & \multicolumn{3}{|c|}{ Linear regression analysis } \\
\hline \multicolumn{2}{|c|}{ Demographic and social factors } & $\beta$ & $95 \% C I$ & $P$ \\
\hline \multicolumn{2}{|l|}{ Age } & -0.011 & $-0.411-0.017$ & 0.429 \\
\hline \multicolumn{2}{|l|}{ Male gender } & -0.110 & $-0.161-0.059$ & $<0.001$ \\
\hline \multicolumn{2}{|l|}{ Internet accessibility } & 0.006 & $0.003-0.009$ & $<0.001$ \\
\hline \multicolumn{2}{|l|}{ Metropolitan areas } & 0.196 & $0.141-0.251$ & $<0.001$ \\
\hline \multirow[t]{2}{*}{ Household composition } & Student does not live with biological parent or relative & 0.681 & $0.471-0.892$ & $<0.001$ \\
\hline & Student has no siblings & 0.105 & $0.038-0.173$ & 0.002 \\
\hline \multirow[t]{3}{*}{ Birth in another country } & Father of student was born in another country & -0.038 & $-0.161-0.084$ & 0.539 \\
\hline & Mother of student was born in another country & 0.061 & $-0.034-0.157$ & 0.212 \\
\hline & Student was born in another country & 0.048 & $-0.049-0.146$ & 0.333 \\
\hline \multirow[t]{3}{*}{ Parental involvement } & Parents do not understand student's problems & 0.306 & $0.246-0.367$ & $<0.001$ \\
\hline & Parents do not know what student does with free time & 0.410 & $0.351-0.469$ & $<0.001$ \\
\hline & Parents do not pay attention to student & 0.313 & $0.254-0.371$ & $<0.001$ \\
\hline \multirow[t]{2}{*}{ Peer relationships } & Student has a steady boyfriend/girlfriend & 0.136 & $0.075-0.198$ & $<0.001$ \\
\hline & Student has no close friends & 0.005 & $-0.249-0.260$ & 0.564 \\
\hline \multirow{2}{*}{$\begin{array}{l}\text { Parental unemployment } \\
\text { Religiosity }\end{array}$} & Unemployment of student's parent/guardian & 0.289 & $0.205-0.373$ & $<0.001$ \\
\hline & Student perceived himself/herself as a religious person & 0.015 & $-0.038-0.070$ & 0.564 \\
\hline
\end{tabular}

aThe regression coefficients represent differences of the mean score per unit of the respective variable. CI: confidence interval. Significance level of $P<0.05$. 
Adolescents without siblings have demonstrated an increased risk of loneliness [69]. In this study, having no siblings was associated significantly with higher YDQ scores. Thus, adolescent PIUs may potentially become alienated from normal socialization, thereby perpetuating lower social and communication skills. In a longitudinal investigation, Van den Eilnden et al. [70] found a negative correlation between loneliness and instant messaging; this suggests that isolated individuals do not utilize the internet for communication purposes. As a result, the risk emerges of ensuing social and psychological problems.

In the present study, PIUs appeared to prefer specific online activities. When engaging in specific online activities, there is a tendency for these users to stay online longer than intended. This could be due to the widespread use of multi-tasking online or intense interaction to a specific application. In many instances, users go online to simply surf the web. While surfing the web, users may search actively for specific websites or encounter activities that appear alluring. Interactive websites, such as gaming, chatting and social networking, stimulate the internet user psychologically, thereby tantalizing the user to remain online for longer than anticipated. Certain websites are tailored specifically for enticing idiosyncratic age groups, particularly adolescent users. Youth engaging in such online activities are potentially captivated by the activity, resulting in successive cravings to return to that specific application. In our study, gaming, chatting and social networking were highly ranked activities among adolescents; these contingencies underscore the significance of virtual interaction in online activities and subsequent addiction. There is a need for qualitative studies in this area, as it would help to elucidate commonalities practised on the internet (e.g. multiple tabbing); it could also verify if adolescent PIUs compulsively search for new activities or are enticed by interactive websites, crave specific online applications or virtual communication.

The most robust findings from our study concern household conditions. Adolescents living without a biological parent, low parental involvement and parental unemployment were the most influential factors in determining MIU and PIU. Evidence shows that risk behaviours are known correlates of subsiding familial relationships with regard to school activities, social life, outside activities, supervision and monitoring of the adolescent [71,72]. Generally, adolescent risk behaviours (e.g. substance use) are performed outside the household, usually unbeknown to their parents; however, PIU often occurs within the household, with their parents' knowledge. Adolescents with a lack of familial support potentially use the internet as a virtual substitute to cope. This, in turn, may increase the propensity for incipient risky and pathological behaviours.
Parental unemployment was also a significant factor. Adolescents with parents/guardians who were unemployed reported a significantly higher risk of PIU. Parental unemployment may lead to a shift of focus away from the adolescent and towards the problematic employment situation, resulting in low parental engagement. This finding is relatively new for PIU, but does coincide with previous research that underlines parental unemployment as a substantial contributory factor for other risk behaviours.

Fathers born in another country increased the relative risk of MIU; however, this association was not found for adolescents or mothers born in another country. Further research is needed to understand the role of the father in adolescent internet use.

Concerning peer relationships, adolescents reporting a steady girlfriend/boyfriend appeared to have an increased risk of PIU. This finding requires further analysis, as there are potential psychological factors confounding this relationship. However, adolescents with a steady partner typically spend more time communicating with their companion online, as the internet provides substantial opportunities for both visual and audio communication.

\section{Strengths and limitations}

A major strength of this study is the large sample of adolescents, recruited from randomly selected schools, across 11 study sites, which were representative of the respective European country. The students were recruited and evaluated with homogeneous procedures in each country, in terms of inclusion and exclusion criteria and outcome measures. Furthermore, to the extent of our knowledge, this prevalence study on adolescent PIU comprised the largest geographic area ever reported.

A limitation of this study is that the classification of pathological internet behaviours relied solely on selfreport. The data presented here for internet access were obtained on the national level, whereas MIU and PIU were measured on the individual level. Another limitation of this study is that it was not possible to collect information regarding psychosocial factors among students who did not consent to participate; therefore, we were unable to compare responders with non-responders in this regard. However, data on age and gender proportion were collected for both groups, and no significant differences were found.

\section{CONCLUSION}

The prevalence of MIU and PIU among adolescents in Europe was $13.5 \%$ and $4.4 \%$, respectively; females showed higher rates of MIU and males indicated higher rates of PIU. Gender variances were found in nearly all 
examined variables; thus, gender-specific pathways of MIU and PIU need to be scrutinized independently in future research. To our knowledge, this is the first study to show that levels of internet accessibility are not associated with the increased relative risk of PIU. Not living with biological parent(s) and low parental involvement were the most significant contributory social factors of PIU; adolescents lacking emotional and psychological support had the highest risk. These findings suggest that the situation at home, and the relationship with parent(s), have important implications on the psychological health of the adolescent. This largest up-to-date study on PIU prevalence calls for further research examining internet-related behaviours among adolescents and their association with internet accessibility.

\section{Declarations of interest}

None.

\section{Acknowledgements}

The SEYLE project is supported by the European Union through the Seventh Framework Program (FP7), Grant agreement number HEALTH-F2-2009-223091. The SEYLE Project Leader and Principal Investigator is Danuta Wasserman, Professor in Psychiatry and Suicidology, National Centre for Suicide Research and Prevention of Mental Ill-Health (NASP) Karolinska Institutet, Stockholm, Sweden. The Executive Committee comprises Professor Danuta Wasserman and Senior Lecturer Vladimir Carli, both from NASP, Sweden; Professor Marco Sarchiapone, Italy; Professor Christina W. Hoven and Anthropologist Camilla Wasserman, both from Columbia University, NY, USA; the SEYLE Consortium comprises sites in 12 European countries. Site leaders are Danuta Wasserman (NASP, coordinating centre), Christian Haring (Austria), Airi Varnik (Estonia), Jean-Pierre Kahn (France), Romuald Brunner (Germany), Judit Balazs (Hungary), Paul Corcoran (Ireland), Alan Apter (Israel), Marco Sarchiapone (Italy), Doina Cosman (Romania), Dragan Marusic (Slovenia) and Julio Bobes (Spain). In addition, special thanks to: Mária Bálint, Ágnes Keresztény, Luca Farkas and Julia Gádoros from Hungary; the Estonian Ministry of Social Affairs for the financial support and all researchers and other staff participating in the implementation of the SEYLE project in Estonia, in particular Peeter Värnik and Mari Jushkin; at the University of Oviedo-CIBERSAM, M ${ }^{\mathrm{a}}$ Paz García-Portilla, Manuel Bousoño, Susana Al-Halabí, Ma Teresa Bascarán, Eva Mª Díaz-Mesa, Marlen Garrido, Patricia Buron, Jose Luis Rancaño and Gonzalo Galvan; Gloria Fischer and Katja Klug from the University of Heidelberg in Germany; and Miriam Iosue, Marianna D'Aulerio and Francesco Basilico at University of Molise in Italy.

\section{References}

1. InternetWorldStats. Usage and Population Statistics Miniwatts Marketing Group. 2010. Available at: http://www. internetworldstats.com/ (accessed 8 October 2010) (Archived at http://www.webcitation.org/68XG6oyjj).

2. Bremer J. The internet and children: advantages and disadvantages. Child Adolesc Psychiatr Clin N Am 2005; 14: 40528.

3. Greenfield P., Yan Z. Children, adolescents, and the internet: a new field of inquiry in developmental psychology. Dev Psychol 2006; 42: 391-4.

4. Guan S. S., Subrahmanyam K. Youth internet use: risks and opportunities. Curr Opin Psychiatry 2009; 22: 351-6.

5. Shaw M., Black D. W. Internet addiction: definition, assessment, epidemiology and clinical management. CNS Drugs 2008; 22: 353-65.

6. Chou C., Condron L., Belland J. C. A review of the research on internet addiction. Educ Psychol Rev 2005; 17: 363-88.

7. Wanajak K., Rudd C., Wilkinson A. Definition and diagnostic criteria of internet addiction. Int J Ment Health Nurs 2008; 17: A32-A3.

8. Block J. J. Issues for DSM-V: internet addiction. Am J Psychiatry 2008; 165: 306-7.

9. Pies R. Should DSM-V designate 'internet addiction' a mental disorder? Psychiatry (Edgmont) 2009; 6: 31-7.

10. Dowling N. A., Quirk K. L. Screening for internet dependence: do the proposed diagnostic criteria differentiate normal from dependent internet use? Cyberpsychol Behav 2009; $12: 21-7$.

11. Griffiths M. Addiction, the tobacco industry and nature. Nature 1998; 392: 122.

12. Griffiths M. Behavioural addiction: an issue for everybody? J Workplace Learn 1996; 8: 19-25.

13. van Rooij A. J., Schoenmakers T. M., van de Eijnden R. J., van de Mheen D. Compulsive internet use: the role of online gaming and other internet applications. J Adolesc Health 2010; 47: 51-7.

14. van den Eijnden R. J. J. M., Meerkerk G. J., Vermulst A. A., Spijkerman R., Engels R. C. M. E. Online communication, compulsive internet use, and psychosocial well-being among adolescents: a longitudinal study. Dev Psychol 2008; 44: 655-65.

15. Holden C. Psychiatry. Behavioral addictions debut in proposed DSM-V. Science 2010; 327: 935.

16. Aboujaoude E., Koran L. M. Prevalence underestimated in problematic internet use study-response. CNS Spectr 2007; 12: 14-5.

17. Aboujaoude E., Koran L. M., Gamel N., Large M. D., Serpe R. T. Potential markers for problematic internet use: a telephone survey of 2513 adults. CNS Spectr 2006; 11: 750-5.

18. Morahan-Martin J., Schumacher P. Incidence and correlates of pathological internet use among college students. Comput Hum Behav 2000; 16: 13-29.

19. Greenfield D. N. Psychological characteristics of compulsive internet use: a preliminary analysis. Cyberpsychol Behav 1999; 2: 403-12.

20. Cao F., Su L. Internet addiction among Chinese adolescents: prevalence and psychological features. Child Care Health Dev 2007; 33: 275-81.

21. Leung L. Net-generation attributes and seductive properties of the internet as predictors of online activities and internet addiction. Cyberpsychol Behav 2004; 7: 333-48. 
22. Deng Y. X., Hu M., Hu G. Q., Wang L. S., Sun Z. Q. [An investigation on the prevalence of internet addiction disorder in middle school students of Hunan province]. Zhonghua Liu Xing Bing Xue Za Zhi 2007; 28: 445-8.

23. Xu J., Shen L. X., Yan C. H., Wu Z. Q., Ma Z. Z., Jin X. M. et al. [Internet addiction among Shanghai adolescents: prevalence and epidemiological features]. Zhonghua Yu Fang Yi Хиe Za Zhi 2008; 42: 735-8.

24. Chou C., Hsiao M. C. Internet addiction, usage, gratification, and pleasure experience: the Taiwan college students' case. Comput Educ 2000; 35: 65-80.

25. Yoo H. J., Cho S. C., Ha J., Yune S. K., Kim S. J., Hwang J. et al. Attention deficit hyperactivity symptoms and internet addiction. Psychiatry Clin Neurosci 2004; 58: 487-94.

26. Park S. K., Kim J. Y., Cho C. B. Prevalence of internet addiction and correlations with family factors among South Korean adolescents. Adolescence 2008; 43: 895-909.

27. Kaltiala-Heino R., Lintonen T., Rimpela A. Internet addiction? Potentially problematic use of the internet in a population of 12-18-year-old adolescents. Addict Res Theory 2004; 12: 89-96.

28. Pallanti S., Bernardi S., Quercioli L. The Shorter PROMIS Questionnaire and the Internet Addiction Scale in the assessment of multiple addictions in a high-school population: prevalence and related disability. CNS Spectr 2006; 11 : 966-74.

29. Zboralski K., Orzechowska A., Talarowska M., Darmosz A., Janiak A., Janiak M. et al. The prevalence of computer and internet addiction among pupils. Postepy Hig Med Dosw (Online) 2009; 63: 8-12.

30. Siomos K. E., Dafouli E. D., Braimiotis D. A., Mouzas O. D., Angelopoulos N. V. Internet addiction among Greek adolescent students. Cyberpsychol Behav 2008; 11: 653-7.

31. Young K. Internet addiction: the emergence of a new clinical disorder. CyberPsychol Behav 1998; 1: 237-44.

32. Johansson A., Gotestam K. G. Internet addiction: characteristics of a questionnaire and prevalence in Norwegian youth (12-18 years). Scand J Psychol 2004; 45: 223-9.

33. Tsai H. F., Cheng S. H., Yeh T. L., Shih C. C., Chen K. C., Yang Y. C. et al. The risk factors of internet addiction-a survey of university freshmen. Psychiatry Res 2009; 167: 2949.

34. Bakken I. J., Wenzel H. G., Gotestam K. G., Johansson A., Oren A. Internet addiction among Norwegian adults: a stratified probability sample study. Scand J Psychol 2008; 50: 121-7.

35. Yen J. Y., Yen C. F., Chen C. C., Chen S. H., Ko C. H. Family factors of internet addiction and substance use experience in Taiwanese adolescents. Cyberpsychol Behav 2007; 10: 323-9.

36. Milani L., Osualdella D., Di Blasio P. Quality of interpersonal relationships and problematic Internet use in adolescence. Cyberpsychol Behav 2009; 12: 681-4.

37. Hur M. H. Demographic, habitual, and socioeconomic determinants of internet addiction disorder: an empirical study of Korean teenagers. Cyberpsychol Behav 2006; 9: 514-25.

38. Reijneveld S. A., Veenstra R., de Winter A. F., Verhulst F. C., Ormel J., de Meer G. Area deprivation affects behavioral problems of young adolescents in mixed urban and rural areas: the TRAILS study. J Adolesc Health 2010; 46: 18996.

39. Carpenter-Song E., Chu E., Drake R. E., Ritsema M., Smith B., Alverson H. Ethno-cultural variations in the experience and meaning of mental illness and treatment: implications for access and utilization. Transcult Psychiatry 2010; 47: 224-51.

40. Geppert C., Bogenschutz M. P., Miller W. R. Development of a bibliography on religion, spirituality and addictions. Drug Alcohol Rev 2007; 26: 389-95.

41. Volkow N. D., Wise R. A. How can drug addiction help us understand obesity? Nat Neurosci 2005; 8: 555-60.

42. Lester D. Access to gambling opportunities and compulsive gambling. Int J Addict 1994; 29: 1611-16.

43. Pearce J., Mason K., Hiscock R., Day P. A national study of neighbourhood access to gambling opportunities and individual gambling behaviour. J Epidemiol Commun Health 2008; 62: 862-8.

44. Wilson D. H., Gilliland J., Ross N. A., Derevensky J., Gupta R. Video lottery terminal access and gambling among high school students in Montreal. Can J Public Health 2006; 97 : 202-6.

45. Carter B. L., Tiffany S. T. Meta-analysis of cue-reactivity in addiction research. Addiction 1999; 94: 327-40.

46. Wasserman D., Carli V., Wasserman C., Apter A., Balazs J., Bobes J. et al. Saving and Empowering Young Lives in Europe (SEYLE): a randomized controlled trial. BMC Public Health 2010; 10: 192.

47. Cao F., Su L., Liu T., Gao X. The relationship between impulsivity and internet addiction in a sample of Chinese adolescents. Eur Psychiatry 2007; 22: 466-71.

48. Goodman A. Addiction: definition and implications. $\mathrm{Br} \mathrm{J}$ Addict 1990; 85: 1403-8.

49. World Health Organization (WHO). Global School-Based Student Health Survey. Geneva: World Health Organization; 2009. Available at: http://www.who.int/chp/gshs/en/ (accessed 13 November 2010) (Archived at http://www. webcitation.org/68XGEdjad).

50. European Values Study (EVS). The European Values Study Questionnaire. the Netherlands: Tilburg University; 2009. Available at: http://www.europeanvalues.nl/ (accessed 2 September 2010) Archived at http://www.webcitation.org/ 68XGKA1rk).

51. Eurostat. Statistics: Computers and the Internet in Households and Enterprises. European Union. 2010. Available at: http://epp.eurostat.ec.europa.eu/portal/page/portal/ information_society/data/main_tables (accessed 4 February 2011) (Archived at http://www.webcitation.org/ 68XGMtJIx).

52. Eurostat. Statistics database. European Union. 2010. Available at: http://epp.eurostat.ec.europa.eu/portal/ page/portal/eurostat/home/ (accessed 31 January 2011) (Archived at http://www.webcitation.org/68XGQxy50).

53. Cohen J. Statistical Power Analysis for the Behavioral Sciences. Hillsdale, NJ: Lawrence Erlbaum Associates; 1988.

54. Cohen J., Cohen P. Applied Multiple Regression/Correlation Analysis for the Behavioral Sciences, 2nd edn. Hillsdale, NJ: L. Erlbaum Associates; 1983.

55. Telhaj S., Hutton D., Davies P., Adnett N., Coe R. Competition Within Schools: Representativeness of Yellis Sample Schools in a Study of Subject Enrollment of 14-16 Year Olds. 2004. Institute for Education Policy Research, Staffordshire University. Working Paper no. 2004/11. Available at: http://www. staffs.ac.uk/schools/business/iepr/docs/Working-paper11. pdf (accessed 10 June 2011) (Archived at http://www. webcitation.org/68XGVE9qA).

56. Buuren S., Oudshoorn K. Flexible multivariate imputation by MICE. TNO Prevention and Health, Leiden 1999. 
57. Rubin D. B. Multiple Imputation for Nonresponse in Surveys. Hoboken: John Wiley \& Sons, Inc.; 2008.

58. Mueser K. T., Yarnold P. R., Levinson D. F., Singh H., Bellack A. S., Kee K. et al. Prevalence of substance abuse in schizophrenia: demographic and clinical correlates. Schizophr Bull 1990; 16: 31-56.

59. Brunette M. F., Mueser K. T., Xie H., Drake R. E. Relationships between symptoms of schizophrenia and substance abuse. J Nerv Ment Dis 1997; 185: 13-20.

60. Ibanez A., Perez de Castro I., Fernandez-Piqueras J., Blanco C., Saiz-Ruiz J. Pathological gambling and DNA polymorphic markers at MAO-A and MAO-B genes. Mol Psychiatry 2000; 5: 105-9.

61. Ibanez A., Blanco C., Perez de Castro I., Fernandez-Piqueras J., Saiz-Ruiz J. Genetics of pathological gambling. J Gambl Stud 2003; 19: 11-22.

62. Potenza M. N. The neurobiology of pathological gambling. Semin Clin Neuropsychiatry 2001; 6: 217-26.

63. Kormas G., Critselis E., Janikian M., Kafetzis D., Tsitsika A. Risk factors and psychosocial characteristics of potential problematic and problematic internet use among adolescents: a cross-sectional study. BMC Public Health 2011; 11: 595.

64. Aslanidou S., Menexes G. Youth and the internet: uses and practices in the home. Comput Educ 2008; 51: 1375-91.

65. Ceyhan A. A. Predictors of problematic internet use on Turkish university students. Cyberpsychol Behav 2008; 11: 363-6.

66. Ko C. H., Yen J. Y., Chen C. C., Chen S. H., Yen C. F. Gender differences and related factors affecting online gaming addiction among Taiwanese adolescents. J Nerv Ment Dis 2005; 193: 273-7.

67. Campbell A. J., Cumming S. R., Hughes I. Internet use by the socially fearful: addiction or therapy? Cyberpsychol Behav 2006; 9: 69-81.

68. Paul B., Bryant J. A. Adolescents and the internet. Adolesc Med Clin 2005; 16: 413-26, x.

69. Lasgaard M., Nielsen A., Eriksen M. E., Goossens L. Loneliness and social support in adolescent boys with autism spectrum disorders. J Autism Dev Disord 2010; 40: 218-26.

70. van den Eijnden R. J., Meerkerk G. J., Vermulst A. A., Spijkerman R., Engels R. C. Online communication, compulsive internet use, and psychosocial well-being among adolescents: a longitudinal study. Dev Psychol 2008; 44: 655-65.

71. Chirita V., Chirita R., Stefanescu C., Chele G., Ilinca M. Computer use and addiction in Romanian children and teenagers-an observational study. Rev Med Chir Soc Med Nat Iasi 2006; 110: 526-32.

72. Lin C. H., Lin S. L., Wu C. P. The effects of parental monitoring and leisure boredom on adolescents' internet addiction. Adolescence 2009; 44: 993-1004.

73. Central Bureau of Statistics (CBS). Central Bureau of Statistics: Household Expenditure Survey-Ownership of Durable Goods and Housing Data. Israel: National Public Council for Statistics; 2010. Available at: http://www1.cbs.gov.il/ reader/cw_usr_view_Folder?ID=141 (accessed 20 June 2011) (Archived at http://www.webcitation.org/ 68XGadKdd).

\section{Supporting Information}

Additional Supporting Information may be found in the online version of this article:

Table S1. Response rates for all Saving and Empowering Young Lives in Europe (SEYLE) countries.

Table S2. Response rates for eight countries (Austria, France and Slovenia were excluded).

Table S3a. Multinomial regression model of Young Diagnostic Questionnaire for Internet Addiction (YDQ) categories by demographic and social factors. ${ }^{a}$

Table S3b. Multinomial regression model of Young Diagnostic Questionnaire for Internet Addiction (YDQ) categories by demographic and social factors; ${ }^{a}$ Austria, France and Slovenia excluded from the analyses.

Table S4a. Linear regression model of Young Diagnostic Questionnaire for Internet Addiction (YDQ) total score by demographic and social factors. ${ }^{a}$

Table S4b. Linear regression model of Young Diagnostic Questionnaire for Internet Addiction (YDQ) total score by demographic and social factors; ${ }^{\mathrm{a}}$ Austria, France and Slovenia excluded from the analyses.

\section{APPENDIX}

Item Yes No

1. Do you feel preoccupied with the internet (i.e. think about previous online activity or anticipate next online session)?

2. Do you feel the need to use the internet with increasing amounts of time in order to achieve satisfaction?

3. Have you repeatedly made unsuccessful efforts to control, cut back or stop internet use?

4. Do you feel restless, moody, depressed or irritable when attempting to cut down or stop internet use?

5. Do you stay online longer than originally intended?

6. Have you jeopardized or risked the loss of significant relationship, job, or educational opportunity because of the internet?

7. Have you lied to family members, therapist or others to conceal the extent of involvement with the internet?

8. Do you use the internet as a way of escaping from problems or of relieving a dysphonic mood (e.g. feelings of helplessness, guilt, anxiety or depression)? 